\title{
Comparison of the effects of two GnRH antagonists on LH and FSH secretion, follicular growth and ovulation in the mare
}

\author{
Daniel Guillaume*, Bernard Bruneau, \\ Christine BRIANT \\ Physiologie de la Reproduction et des Comportements, \\ Institut National de la Recherche Agronomique (INRA), 37380 Nouzilly, France
}

(Received 11 December 2001; accepted 30 May 2002)

\begin{abstract}
The effects of two GnRH antagonists were tested in order to delay and/or synchronise ovulation in mares. Five mares received Antarelix $\left(0.01 \mathrm{mg} \cdot \mathrm{kg}^{-1}\right), 5$ mares received Cetrorelix (the same dose), 5 mares (control mares) received the vehicle intravenously, twice daily, for 8 days from the day the largest follicle reached $22 \mathrm{~mm}$ following prostaglandin administration. Ovulation was postponed in all mares injected with Antarelix (19.4 \pm 1.2 days after the beginning of the treatment) and in 2/5 mares injected with Cetrorelix ( $20 \pm 1$ days) vs. $6.2 \pm 0.4$ days in control mares. During the treatment, LH concentrations were strongly depressed in Antarelix and in Cetrorelix mares (1.6 \pm 0.1 and $3.8 \pm 0.5 \mathrm{ng} \cdot \mathrm{mL}^{-1}$ respectively vs. $21 \pm 2.5 \mathrm{ng} \cdot \mathrm{mL}^{-1}$ in control mares). In the 3 Cetrorelix mares which ovulated during the treatment, 2 initiated their LH surge at this moment. FSH concentrations were not affected in Antarelix or in Cetrorelix mares during the treatment $(11.4 \pm 1.3$ and $7.9 \pm$ $0.8 \mathrm{ng} \cdot \mathrm{mL}^{-1}$ respectively vs. $10.5 \pm 0.8 \mathrm{ng} \cdot \mathrm{mL}^{-1}$ in control mares). In conclusion, Antarelix seems more efficient than Cetrorelix for postponing ovulation in mares. The role of LH in antral follicular development before the preovulatory stage is confirmed.
\end{abstract}

mare / GnRH antagonist / ovulation / FSH / LH

* Correspondence and reprints
E-mail: dguillau@tours.inra.fr 


\section{INTRODUCTION}

GnRH antagonists can be used to delay and synchronise the LH surge and ovulation in different species: heifers [24], gilts [29], goats [2], ewes [8] and in ovarian stimulation cycles for IVF in humans namely to prevent premature LH surge [1]. These antagonists are also of interest for studying requirements in gonadotrophin support for terminal follicular growth [6]. The use of GnRH antagonists in equine breeds should be interesting in mares, to delay and/or synchronise ovulation for insemination in commercial mares; they could also be of interest in association with superovulation treatments, to regulate endogenous gonadotrophins, namely $\mathrm{LH}$, which seems to interfere with exogenous injected LH, possibly involved in the poor results of fertility obtained with these treatments [3]. Only two studies using a GnRH antagonist have been conducted in mares. The GnRH antagonist (ORG 30583) inhibits $\mathrm{LH}$ and ovulation at the dose of $0.04 \mathrm{mg} / \mathrm{kg} / \mathrm{day}, \mathrm{IM}$, and synchronises ovulation $14.3 \pm 0.5$ days after the end of a 15-day treatment, when treatment began at different times of the cycle, oestrus or dioestrus [28]. The GnRH antagonist, Antarelix, injected $\left(0.1 \mathrm{mg} \cdot \mathrm{kg}^{-1}, \mathrm{SC}\right)$ on day 8 of dioestrus eliminates $\mathrm{LH}$ dioestrous pulses and delays ovulation for approximately 9.5 days [33].

The aim of the present study was to compare the effects of two GnRH antagonists, one of them (Antarelix) rather used in domestic species, the other one (Cetrorelix) in the human species and to determine if they have the same potency to delay and/or synchronise ovulation in mares. To reduce the variability of the potential response, in terms of time for follicular growth, we chose to inject the antagonist, just after the selection of the dominant follicle and by the IV route to induce homogenous circulating concentrations of the antagonist.

Antarelix (Ac-D-Nal, D-Phe(pCI), D-Pal, Ser, Tyr, D-Hci, Leu, Lys-(iPr), Pro,
D-Ala- $\mathrm{NH}_{2}$, Teverelix, Europeptides, Argenteuil, France) is a water soluble GnRH antagonist [9], which has been tested in some domestic species: gilts $[4,11]$, ewes [27], cows [26] and more recently in mares [33]. Cetrorelix (Ac-D-Nal, D-Phe(pCI), D-Pal, Ser, Tyr, D-Hci, Leu, Arg, (iPr), Pro, D-Ala-Nh 2 Asta Medica, Frankfurt Germany) is also a water soluble GnRH antagonist used in rodents for experimental purposes [31], in superovulated zebu calves [23], and in humans for clinical uses [1].

\section{MATERIALS AND METHODS}

\subsection{Treatments}

The study was performed from the end of August until the end of September. Eighteen cycling pony mares (B.W.: $269 \pm 9 \mathrm{~kg}$; age: $6.6 \pm 1.2$ years old, means \pm S.E.M.) were first synchronised with vaginal sponges impregnated with progestagen $(500 \mathrm{mg}$ of Altrenogest/sponge, Regumate ${ }^{\circledR}$, Hoechst Roussel Vet, Romainville, France) and oestrogen (50 mg of beta-estradiol 3 benzoate/sponge, Sigma E8515) [12]. When the sponges were removed 7 days later, pony mares received an $\mathrm{IM}$ injection of $\mathrm{PGF}_{2}$ alpha $\left(0.5 \mathrm{~mL}\right.$, Estrumate ${ }^{\circledR}$, Pitman-Moore, Meaux, France). They were randomly assigned to three groups. The first group was treated with Antarelix, the second with Cetrorelix and the third was used as the control.

Prior to injection, both GnRH antagonists (Antarelix and Cetrorelix) were dissolved in sterile water at a concentration of $0.166 \mathrm{mg} \cdot \mathrm{mL}^{-1}$. $\mathrm{NaCl}$ was added to partially increase osmotic pressure without precipitating the component. The individual doses were kept at $-20{ }^{\circ} \mathrm{C}$ until use. The Antarelix dose $\left(0.01 \mathrm{mg} \cdot \mathrm{kg}^{-1}\right)$ was the same as that used intravenously in gilts $[4,11]$ and in goats [2] and subcutaneously in ewes [8]. For Cetrorelix the same dose was chosen arbitrarily. Antarelix and Cetrorelix were injected twice daily intravenously at a dose of $2.5 \mathrm{mg}$ per injection $\left(0.01 \mathrm{mg} \cdot \mathrm{kg}^{-1}\right)$. 
Because of the low body weight variation between pony mares, doses were not adapted to individual weight. The first daily injection was given between 09:00 and 10:00 AM and the second between 09:00 and 10:00 PM. The treatment began when the largest follicle had reached the diameter of $22 \mathrm{~mm}$, before the mares expressed behavioural or clinical signs of oestrus, and was applied for 8 days or until ovulation if ovulation occurred during the treatment. The animals in the control group received equivalent injections of the vehicle.

\subsection{Ovarian activity}

Ovarian activity (diameters of all the follicles larger than $10 \mathrm{~mm}$ and ovulations) was assessed daily by rectal palpation and transrectal ultrasonography (Aloka SS-210 DX with $5 \mathrm{MHz}$ transducer, Aloka Inc., Japan), from the injection of PGF $2 \alpha$ until ovulation.

\subsection{Hormones}

FSH and progesterone were assayed in one daily blood sample (at 7:00 AM) and LH in three daily blood samples (at 7:00 AM, 02:00 PM and 09:00 PM), from the day of prostaglandin injection to four days after ovulation.

Plasma gonadotrophins were assayed using specific validated radio-immunoassay (R.I.A.) procedures. The equine FSH R.I.A. used a specific antibody [12]; the cross reactions with eLH did not exceed $3 \%$. The equine LH R.I.A. used an antibody against eCG [5]; the cross reactions with eFSH were $1.5 \%$. Standards of equine gonadotrophins (FSH NHPP AFP 5022B and LH NHPP AFP 5130A) were labelled with ${ }^{125}$ I (using Chloramine $\mathrm{T}$ as oxidant for FSH and Iodogene for LH). All samples were measured twice in the same assay and the location of each sample was randomly assigned. To calculate the concentrations, standards ranging from $0.05 \mathrm{ng} \cdot \mathrm{mL}^{-1}$ to $800 \mathrm{ng} \cdot \mathrm{mL}^{-1}$, were prepared in hypophysectomised horse plasma. From the values of these standards, a 4 parameter logistic function was estimated using SAS software; the inverse of this function was used to calculate the concentration of the samples. The first point where the measured radioactivity was significantly different from the zero concentration was $3 \mathrm{ng} \cdot \mathrm{mL}^{-1}$ for eFSH and $0.8 \mathrm{ng} \cdot \mathrm{mL}^{-1}$ for eLH. Hypophysectomised horse plasma and 3 blood samples collected in other mares, at different times of the cycle, were routinely used as quality controls and were placed every 100 samples. Their concentrations were for eFSH: not detectable, $4 \mathrm{ng} \cdot \mathrm{mL}^{-1}, 24 \mathrm{ng} \cdot \mathrm{mL}^{-1}$ and $25.8 \mathrm{ng} \cdot \mathrm{mL}^{-1}$ with intra-assay $\mathrm{CV}$ of $26 \%$, $9 \%$ and $9 \%$ respectively and for eLH: not detectable, $2.4 \mathrm{ng} \cdot \mathrm{mL}^{-1}, 10.8 \mathrm{ng} \cdot \mathrm{mL}^{-1}$, $21.4 \mathrm{ng} \cdot \mathrm{mL}^{-1}$ with intra-assay $\mathrm{CV}$ of $19 \%$, $6 \%$ and $19 \%$ respectively.

Progesterone was measured with a simplified specific R.I.A. without extraction, adapted from [32], with $\left[{ }^{3} \mathrm{H}\right]$ progesterone as the tracer. The concentration was calculated with the standards $0.5 \mathrm{ng} \cdot \mathrm{mL}^{-1}, 1 \mathrm{ng} \cdot \mathrm{mL}^{-1}$, $1.5 \mathrm{ng} \cdot \mathrm{mL}^{-1}, 4 \mathrm{ng} \cdot \mathrm{mL}^{-1}$ and $8 \mathrm{ng} \cdot \mathrm{mL}^{-1}$ prepared in castrated bovine plasma. A linear regression between the log radioactivity values and the concentrations $\left(R^{2}=0.99\right)$ was used to calculate the sample concentrations. The sensitivity of the assay was $0.5 \mathrm{ng} \cdot \mathrm{mL}^{-1}$. Blood samples collected at different times of the cycle, were routinely used as quality controls and were placed every 100 samples. Their concentrations were: $0.5 \mathrm{ng} \cdot \mathrm{mL}^{-1}$, $1.04 \mathrm{ng} \cdot \mathrm{mL}^{-1}$ and $1.53 \mathrm{ng} \cdot \mathrm{mL}^{-1}$ with intraassay $\mathrm{CV}$ of $7 \%, 5 \%$ and $8 \%$ respectively.

\subsection{Statistical analyses}

The increase in plasma progesterone concentration after ovulation is considered to be linear between the day of ovulation until the fourth day after ovulation and this slope was obtained by a linear regression [25]. The differences between the groups in terms 
of the time of ovulation (interval between the prostaglandin injection and the next ovulation or interval between the beginning of the treatment and the next ovulation) and progesterone slope were analysed using the SAS Anova procedure, with the group as the main effect in the model. Group differences were determined using the Student Newman and Keuls test. Statistical significance was considered when $P<0.01$.

Follicular development (diameter of the largest follicle) and hormone levels ( $\mathrm{LH}$, $\mathrm{FSH}$ ) were analysed using variance analysis for repeated measurements (SAS G.L.M. procedure). One-week periods were used as of the first day of treatment (= D0), from day -7 to day +28 . Group, period and groupperiod interaction were used as the main effects in the model. Differences between the groups were tested using the least squares means method. Mare-period interaction was used as the error term and statistical significance was considered when $P<0.01$. All values are presented as arithmetical means \pm SEM.

\section{RESULTS}

\subsection{Follicular growth, ovulations and progesterone secretion}

In the control group, one mare presented a large dominant follicle which failed to ovulate, luteinised and exhibited progesterone secretion. In one mare assigned to the group treated with Antarelix, the first ovulation occurred before the beginning of the treatment with the ovulating follicle measuring less than $22 \mathrm{~mm}$. In the group treated with Cetrorelix, one mare did not ovulate and began her winter inactivity during the treatment. The results from these 3 mares were excluded and only 5 mares were used in each group for data analysis.

The characteristics of ovarian activity are presented in Table I. The effect of treatment is significant on time to occurrence of ovulation with regards to the time of PGF, or the beginning of the treatment. Ovulation was postponed in 5/5 mares injected with Antarelix (19.4 \pm 1.2 days after the beginning of the treatment) and in 2/5 mares injected with Cetrorelix (20 \pm 1 days) (these

Table I. Ovarian activity.

\begin{tabular}{lccccc}
\hline & $\begin{array}{c}\text { Control } \\
(n=5)\end{array}$ & $\begin{array}{c}\text { Antarelix } \\
(n=5)\end{array}$ & $\begin{array}{c}\text { Cetrorelix } \\
(n=5)\end{array}$ & $\begin{array}{c}\text { Cetrorelix } \\
\text { normal } \\
\text { ovulation } \\
(n=3)\end{array}$ & $\begin{array}{c}\text { Cetrorelix } \\
\text { postponed } \\
\text { ovulation } \\
(n=2)\end{array}$ \\
\hline $\begin{array}{l}\text { Time (days) from PGF2 } \alpha \\
\text { to 1st ovulation (means } \pm \text { SEM) }\end{array}$ & $10 \pm 0.7^{\mathrm{a}}$ & $23.4 \pm 1.9^{\mathrm{b}}$ & $16.8 \pm 3.4^{\mathrm{a}, \mathrm{b}}$ & $11.3 \pm 1.3$ & $25.0 \pm 2.0$ \\
$\begin{array}{l}\text { Time (days) from beginning } \\
\text { of treatment to 1st ovulation } \\
\text { (means } \pm \text { SEM) }\end{array}$ & $6.2 \pm 0.4^{\mathrm{a}}$ & $19.4 \pm 1.2^{\mathrm{b}}$ & $11.6 \pm 3.5^{\mathrm{a}, \mathrm{b}}$ & $6.0 \pm 1.0$ & $20.0 \pm 1.0$ \\
$\begin{array}{l}\text { Time (days) from end of treatment } \\
\text { to 1st ovulation (means } \pm \text { SEM) }\end{array}$ & & & & & \\
$\begin{array}{l}\text { Diameter (mm) of the ovulatory } \\
\text { follicle on the day before ovulation } \\
\text { (means } \pm \text { SEM) }\end{array}$ & & $11.8 \pm 1.3$ & & & \\
\hline
\end{tabular}

a,b Values with different superscripts, between columns are significantly different $(P<0.01)$. 
mares are called "Cetrorelix mares with postponed ovulation") vs. $6.2 \pm 0.4$ days in the 5 control mares. The 3 other mares injected with Cetrorelix ovulated during the treatment ( $6 \pm 1$ days after the beginning of the treatment), as the control mares. These mares are called "Cetrorelix mares with normal ovulation".

The characteristics of follicular growth of the ovulatory and/or largest follicle are shown in Figure 1. In the 5 Antarelix mares,

Figure 1. Mean antral diameter $( \pm$ SEM $)$ of largest follicles, from PGF $2 \alpha$ to ovulation, in mares given the GnRH antagonist, beginning on the day the largest follicle reached $22 \mathrm{~mm}$ (D0), for 8 days or until ovulation if ovulation occurred during treatment in the control group $(n=5)$, the Antarelix group $(n=5)$ and Cetrorelix group divided into animals with normal ovulation $(n=3)$ or postponed ovulation $(n=2)$. The grey area represents the period of treatment. The black arrow represents the times of ovulations.
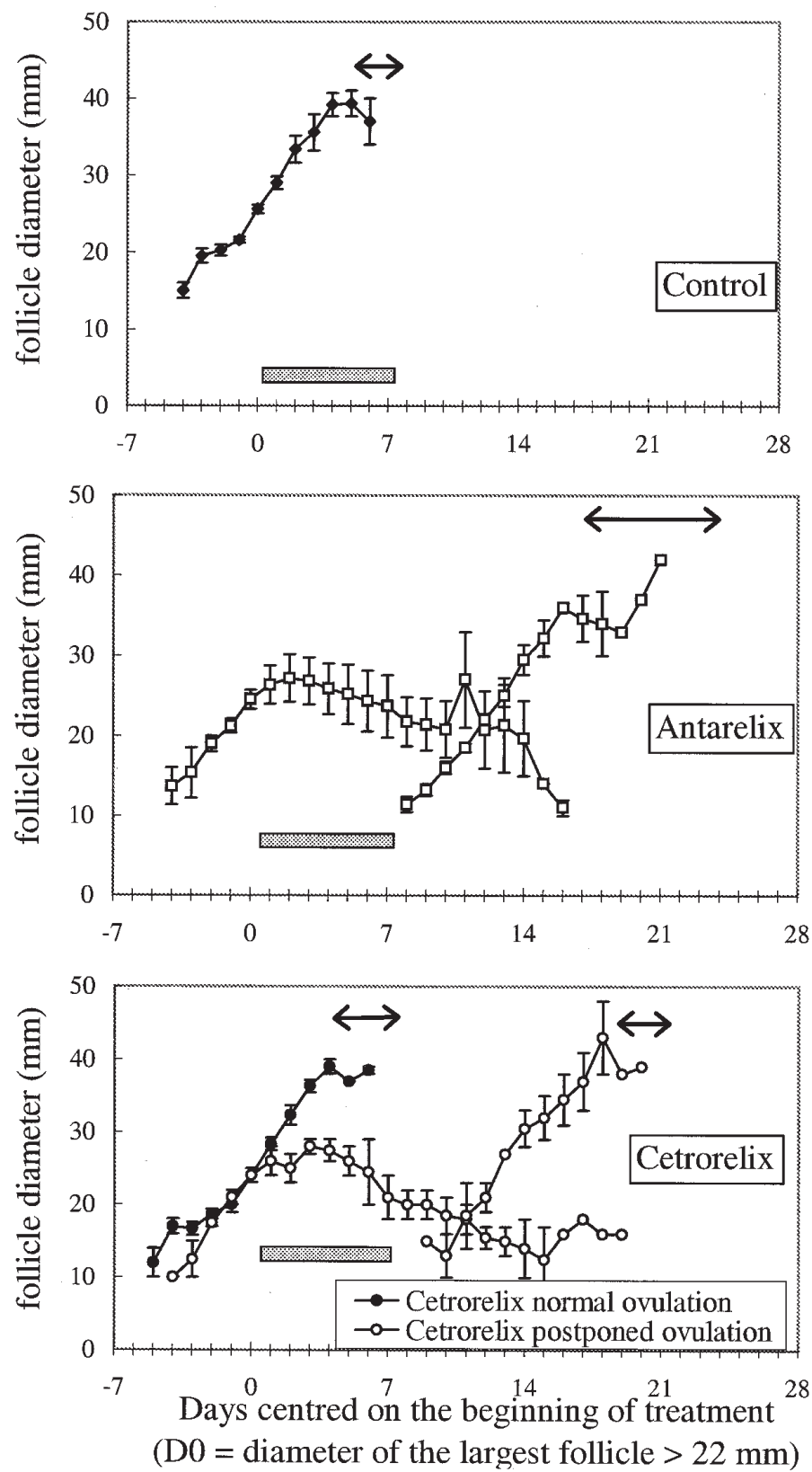
the largest $22 \mathrm{~mm}$ follicle at the beginning of the treatment, kept on growing for 2 days, and then regressed. At the end of the treatment a new $10-15 \mathrm{~mm}$ follicle emerged and ovulated $11.8 \pm 1.3$ days after (respectively $10,10,11,11$ and 17 days for each of the 5 mares). The same profile was observed in the 2 Cetrorelix mares with postponed ovulation (12 and 14 days for each of the 2 mares). In the 3 others, the largest $22 \mathrm{~mm}$ follicle at the beginning of the treatment, kept on growing and ovulated, during the treatment as in the control mares.

The diameter of the ovulatory follicle was not different between the 3 groups.

The increase in progesterone during the 4 days after ovulation (Fig. 2) did not differ between the 3 groups. The slopes of progesterone increase (means \pm SEM (mean of $R^{2}$ calculated for 5 samples after ovulation)) are for the control group, the Antarelix group and the Cetrorelix group respectively: $1.84 \pm 0.26(0.97), 1.64 \pm 0.26(0.95)$ and $1.66 \pm 0.23(0.93)$. In the Cetrorelix group, the progesterone profiles between mares with normal ovulation $(n=3)$ and mares with postponed ovulation $(n=2)$ did not seem to be different; but statistical analysis was not done due to the small numbers of animals in each group.

\subsection{LH and FSH}

Plasma concentrations of $\mathrm{LH}$ and FSH are presented for each group in Figure 3 for LH and Figure 5 for FSH. In the Cetrorelix group, owing to the 2 kinds of responses, individual profiles are also presented for LH in Figure 4 and for FSH in Figure 6.

In the control group, concentrations of LH progressively increased during the 7 days of saline treatment and the LH surge initiated during this period (mean \pm SEM from D1 to D7: $21 \pm 2.5 \mathrm{ng} \cdot \mathrm{mL}^{-1}$ ), ended during the next 7 day period $(30.4 \pm$ $\left.4.2 \mathrm{ng} \cdot \mathrm{mL}^{-1}\right)$. For all the mares in the Antarelix group, the values of LH were strongly depressed, during the period of treatment $\left(1.6 \pm 0.1 \mathrm{ng} \cdot \mathrm{mL}^{-1}\right)$, progressively increased during the first next 7 day period $\left(5.2 \pm 2.3 \mathrm{ng} \cdot \mathrm{mL}^{-1}\right)$ and then reached values of the LH surge at least as elevated $(28 \pm$ $\left.3.2 \mathrm{ng} \cdot \mathrm{mL}^{-1}\right)$ as those in the control group during the next 7 day period. In the Antarelix group, the LH peaks corresponding to ovulation (for the five mares respectively: $13.4,19.4,54.8,111$ and $168 \mathrm{ng} \cdot \mathrm{mL}^{-1}$ ) were in the same range as those in the control group (for the 5 mares respectively: 9.5, $39.6,44.5,90.2$ and $\left.179 \mathrm{ng} \cdot \mathrm{mL}^{-1}\right)$. In the

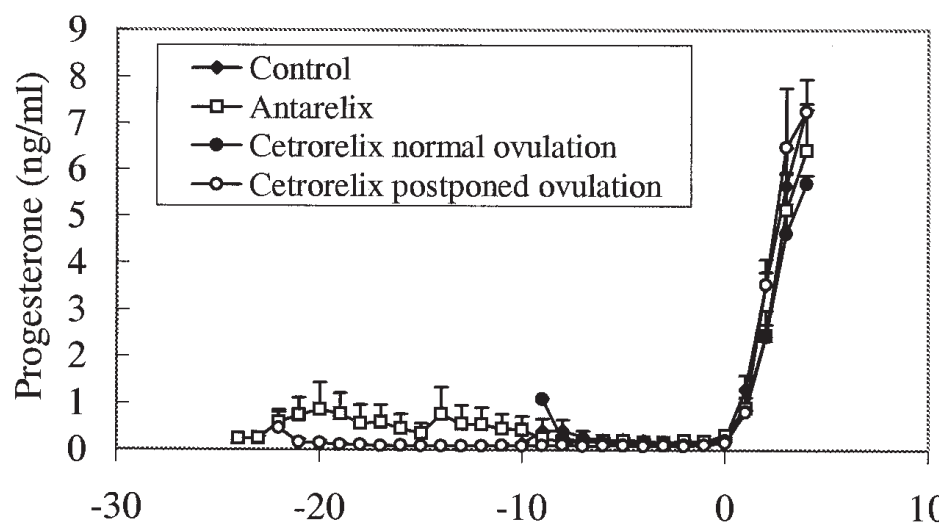

Days centred on ovulation (D0)
Figure 2. Mean plasma $\mathrm{P} 4$ concentrations $( \pm$ SEM), from PGF $2 \alpha$ to 4 days after ovulation, centred on the day of ovulation (D0), in the 3 treatment groups: Control group $(n=5)$, Antarelix group $(n=5)$, and Cetrorelix group divided into animals

with normal ovulation $(n=3)$ or postponed ovulation $(n=2)$. 


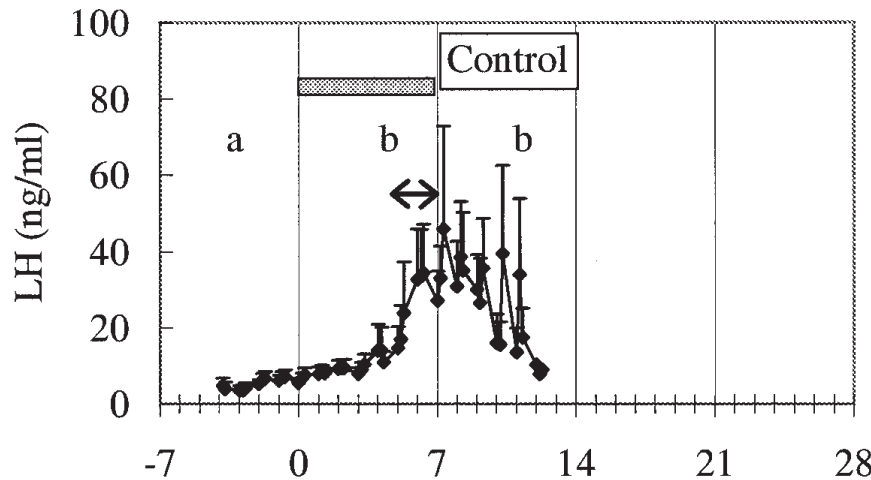

Figure 3. Mean plasma LH concentrations $( \pm$ SEM), from PGF $2 \alpha$ to 4 days after ovulation, in mares given the GnRH antagonist, beginning on the day the largest follicle reached $22 \mathrm{~mm}$ (D0), for 8 days or until ovulation if ovulation occurred during the treatment in: Control group $(n=5)$, Antarelix group $(n=5)$, and Cetrorelix group $(n=5)$. The axis of days is divided into periods of seven days. Periods with different superscripts $(\mathrm{a}-\mathrm{f})$, within each treatment group or between the different treatment groups are significantly different $(P<0.01)$. The grey area represents the period of treatment. The black arrow represents the times of ovulations.
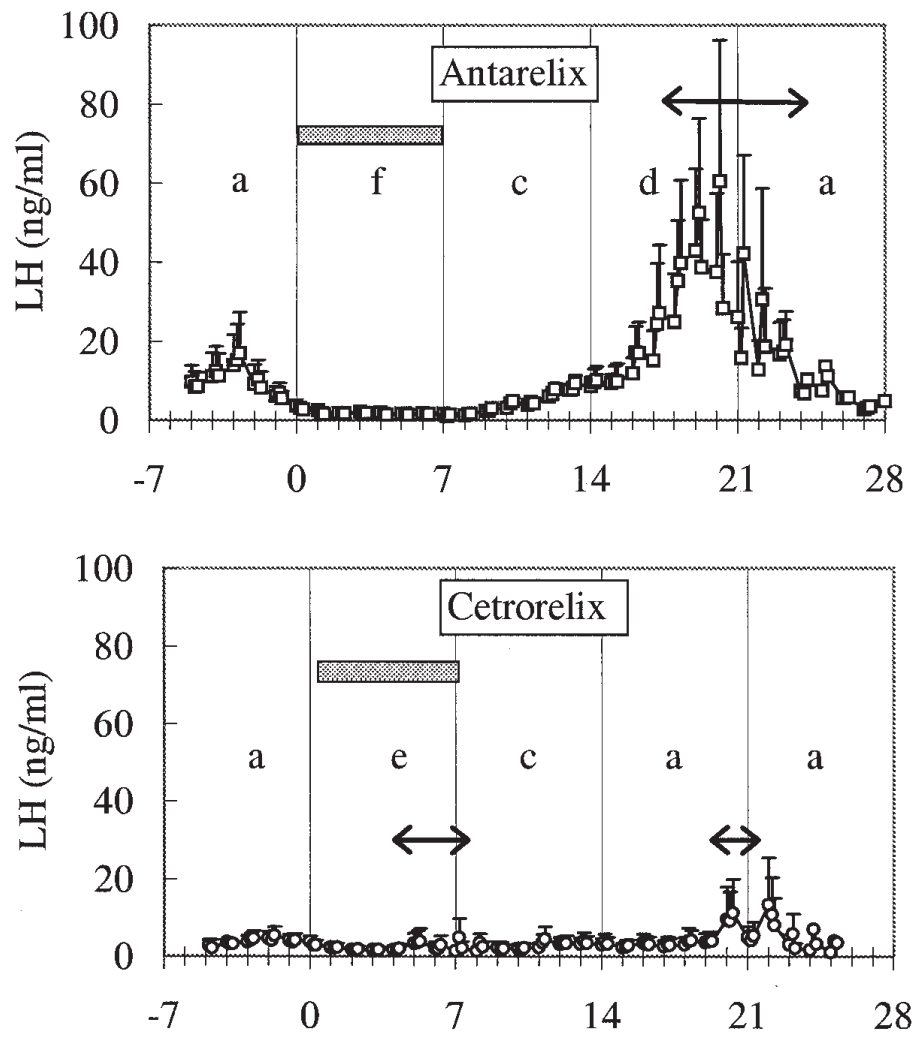

Days centred on the beginning of treatment (D0 $=$ diameter of the largest follicle $>22 \mathrm{~mm}$ )

Cetrorelix group, values of LH were depressed during the period of treatment $\left(3.8 \pm 0.5 \mathrm{ng} \cdot \mathrm{mL}^{-1}\right)$, but less than those in the Antarelix group, increased slightly during the first $\left(4.3 \pm 0.4 \mathrm{ng} \cdot \mathrm{mL}^{-1}\right)$, second $\left(6.3 \pm 0.8 \mathrm{ng} \cdot \mathrm{mL}^{-1}\right)$ and third $(8.7 \pm$ $\left.2.1 \mathrm{ng} \cdot \mathrm{mL}^{-1}\right) 7$ day periods after treatment, but did not reach values as elevated as in 

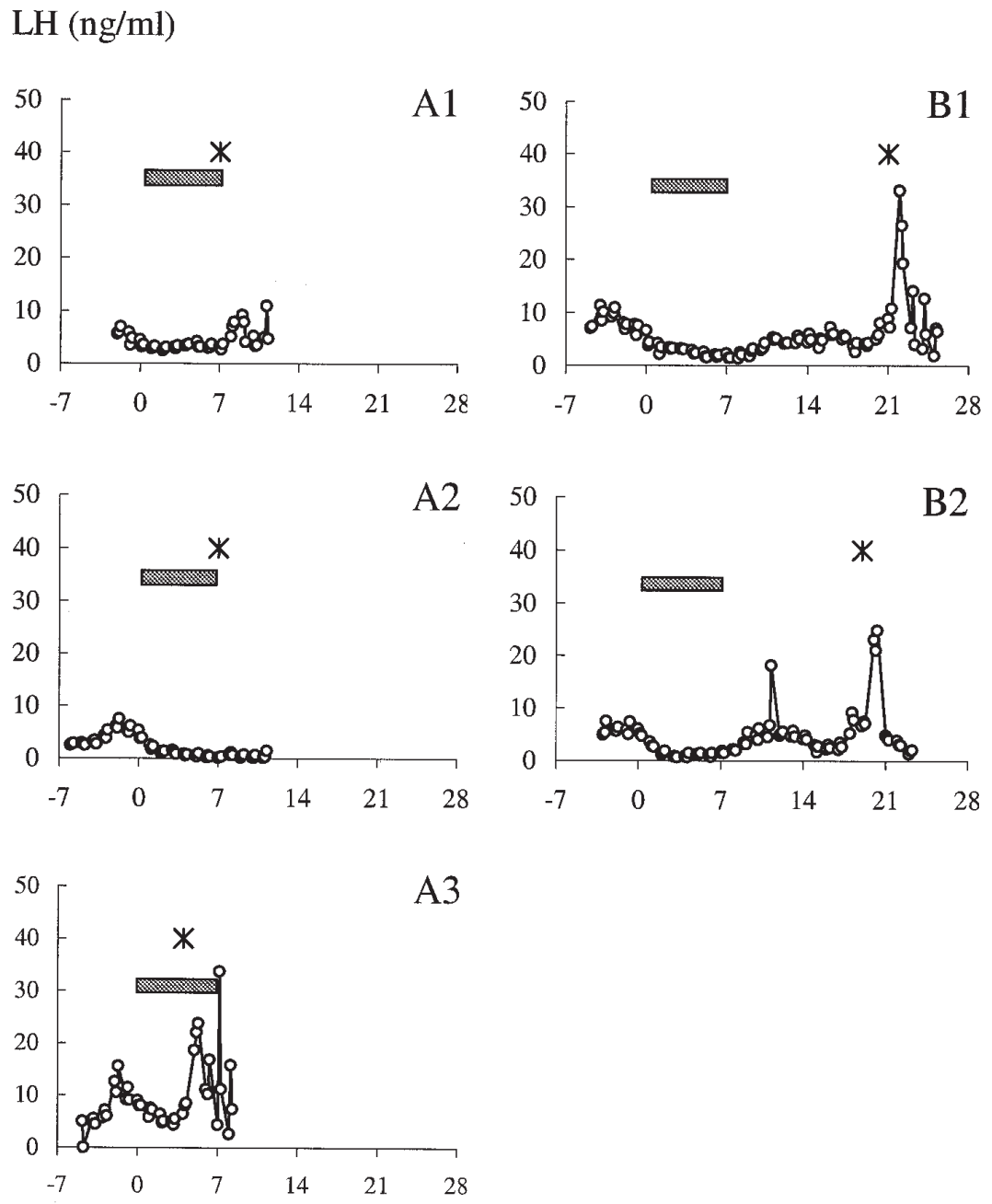

Days centred on the beginning of treatment (D0 $=$ diameter of the largest follicle $>22 \mathrm{~mm}$ )

Figure 4. Individual profiles of plasma LH from PGF2 $\alpha$ to 4 days after ovulation in mares treated with Cetrorelix: (A1, A2, A3) 3 mares with normal ovulation and (B1, B2) 2 mares with postponed ovulation. The grey area represents the period of treatment. The star symbol represents the time of ovulation.

the control group during the LH surge. In the Cetrorelix group with normal ovulation, 2 mares did not respond to the treatment and initiated their LH surges on days 4 and 7 (LH peaks: 9.2 and 23.7 ng. $\mathrm{mL}^{-1}$ respectively); the other mare with normal ovulation did not present any LH surge $\left(1.2 \mathrm{ng} \cdot \mathrm{mL}^{-1}\right)$. In the Cetrorelix group with postponed ovulation, the $\mathrm{LH}$ peaks were respectively 33 and $24.8 \mathrm{ng} \cdot \mathrm{mL}^{-1}$. 
Figure 5. Mean plasma FSH concentrations $( \pm$ SEM), from PGF $2 \alpha$ to 4 days after ovulation, in mares given the GnRH antagonist, beginning on the day the largest follicle reached $22 \mathrm{~mm}$ (D0), for 8 days or until ovulation if ovulation occurred during the treatment in: Control group $(n=5)$, Antarelix group $(n=5)$, and Cetrorelix group $(n=5)$. The axis of days is divided into periods of seven days. Periods with different superscripts $(\mathrm{a}-\mathrm{e})$, within each treatment group or between the different treatment groups are significantly different $(P<0.01)$ The grey area represents the period of treatment. The black arrow represents the times of ovulations.
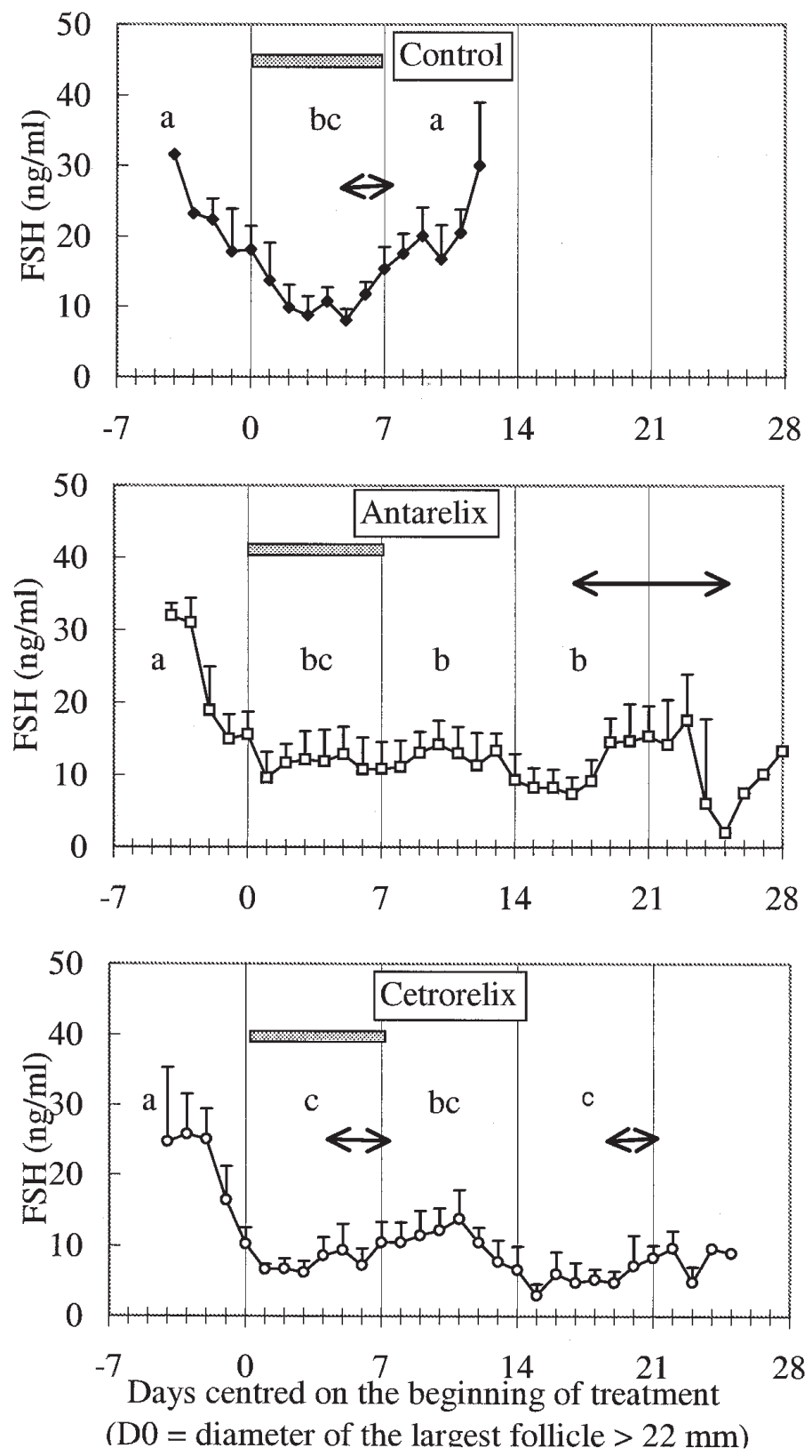

In the control group, FSH concentrations were depressed $\left(10.5 \pm 0.8 \mathrm{ng} \cdot \mathrm{mL}^{-1}\right)$ during the 7 days of treatment compared to the previous $\left(21.4 \pm 1.9 \mathrm{ng} \cdot \mathrm{mL}^{-1}\right)$ and the next $\left(19.2 \pm 1.9 \mathrm{ng} \cdot \mathrm{mL}^{-1}\right) 7$ day periods. In the
Antarelix and Cetrorelix groups, during the 7 days of treatment, concentrations of FSH were also depressed compared to the previous period and were not different from the concentrations observed in the control group 


\section{FSH (ng/ml)}
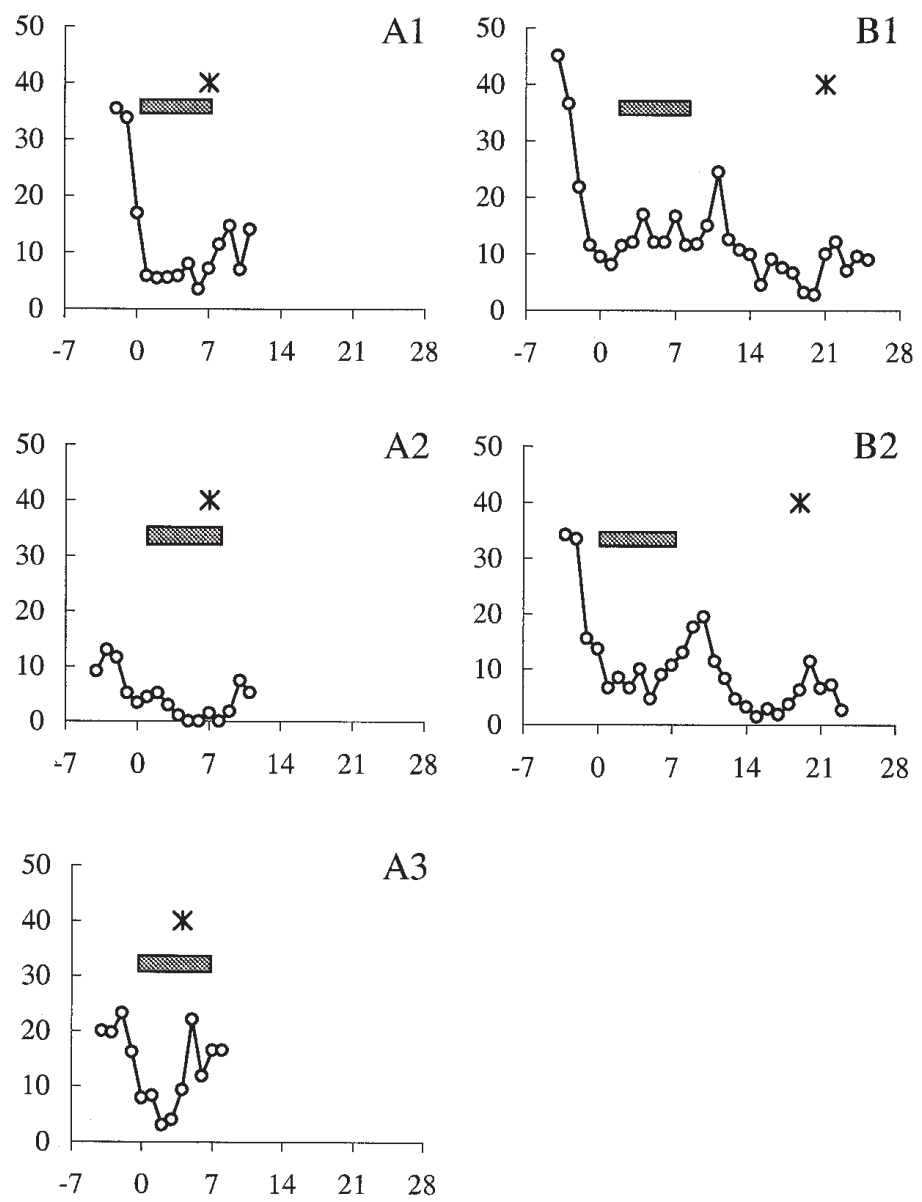

Days centred on the beginning of treatment (D0 = diameter of the largest follicle $>22 \mathrm{~mm}$ )

Figure 6. Individual profiles of plasma FSH from PGF2 $\alpha$ to 4 days after ovulation in mares treated with Cetrorelix: (A1, A2, A3) 3 mares with normal ovulation and (B1, B2) 2 mares with postponed ovulation. The grey area represents the period of treatment. The star symbol represents the time of ovulation.

at the same period. In the 2 treated groups, these concentrations remained at a low level during the first and the second 7 day periods after treatment $(11.4 \pm 1.3$ and $12.2 \pm$ $1.2 \mathrm{ng} \cdot \mathrm{mL}^{-1}$ for the Antarelix group, $11 \pm 2.3$ and $5.6 \pm 0.8 \mathrm{ng} \cdot \mathrm{mL}^{-1}$ for the Cetrorelix group) until the postponed ovulation.
Observation of the individual profiles in the Cetrorelix group showed that in mares with normal ovulation (except for 1 mare) as in mares with postponed ovulation, concentrations of FSH after treatment remained at a low level compared to the pre-treatment levels. In addition in the 2 mares with 
postponed ovulation, during the two 7-day periods after treatment, plasma FSH presented the characteristic profile induced by the dominance of the largest follicle of the second wave but with decreased mean levels as compared to control levels.

\section{DISCUSSION}

The present study compared the effects of the two antagonists Antarelix and Cetrorelix, administered intravenously at the same dose (effective in other species), with the objective to delay and/or to synchronise ovulation. This objective was reached with Antarelix but not with Cetrorelix since 3 mares ovulated during the treatment. With Antarelix and with Cetrorelix in mares with postponed ovulation, the prolongation of the time to ovulation (respectively $11.8 \pm$ 1.3 and $13 \pm 1$ days after the end of treatment), was similar to that observed in the previous experiment using another antagonist at the same moment of the cycle (12.8 \pm 0.9 days) [28], even if the treatment was shorter in the present experiment (8 days vs. 15 days). Synchronisation was good, as indicated by the small variability (except for one mare, ovulations were synchronised for 2 days) These results cannot be compared with the results of Watson et al. [33], who injected the antagonist by the subcutaneous route at a very higher dose; in this experiment the variability of the moment of the postponed ovulation was higher, possibly due to the route of injection (SC) of the antagonist, which induces a longer and less homogeneous availability compared to the IV route; another explanation is the small number of animals. Why Antarelix is more efficient than Cetrorelix could be attributed to their different pharmacokinetics. The data of two studies can be used to compare the pharmacokinetics of Antarelix and Cetrorelix: in humans, after subcutaneous administration of $0.01 \mathrm{mg} \cdot \mathrm{kg}^{-1}$ of Antarelix [15] or Cetrorelix [14], the terminal half-life is longer for Antarelix ( $23 \mathrm{~h}$ ) than for Cetrorelix $(10 \mathrm{~h})$. But these results must be used carefully because the 2 antagonists were not tested in the same study and, in the two studies, the species and routes of administration are different. Concerning the development and maintenance of the corpus luteum after a postponed ovulation, it was quite normal and able to ensure the beginning of a pregnancy, as indicated by the levels of progesterone which were not altered

This study also gives more fundamental results on the effects of the 2 antagonists on $\mathrm{LH}$ and $\mathrm{FSH}$ and on the consequences of the depression of these gonadotrophins on follicular growth and ovulation.

\subsection{Effects on LH and FSH}

In all the mares treated with Antarelix, LH secretion was strongly depressed during the 8 days of IV antagonist treatment, as in mares treated with ORG 30583 IM for 14 days during the follicular phase [28], in gilts treated with Antarelix IV for 4 or 7 days during the preovulatory period [4, 11] and in macaques receiving Antarelix SC for 3 days during the preovulatory period [17]. In all mares, LH secretion began to be restored just after the end of the treatment and reached pre-treatment values 4.5 days after. The LH surge of the postponed ovulation was not altered as in the previous experiment of Palmer [28]. These results confirmed the potency of Antarelix, already demonstrated in other species, for inhibiting LH secretion during the follicular phase in mares, without side-effects on gonadotrophin secretion of the subsequent ovulation. The IV route with two daily injections was a good way to control exactly the time of the inhibition period.

In the Cetrorelix group, the inhibition of LH was less strong. In fact 2 mares initiated their LH surge during the treatment (on the 5th and on the 8th day of treatment) and contributed to increase the mean levels. In other species receiving antagonist treatments, LH surge is either totally abolished or aborted if already initiated in gilts [11], zebu heifers [23] or macaques [17]; in a few 
cases, when antagonists have a delaying effect of 1 to 3 days on the LH surge and ovulation, this surge often attenuated, is observed after the end of the treatment [24]. In the present experiment the $\mathrm{LH}$ peaks seem rather low but are in the normal range of the control mares. Therefore we can consider that these mares did not respond to the treatment because the LH peaks occurred during the treatment and induced ovulation. The third mare which did not respond to Cetrorelix, ovulated without an LH surge. Because of the interval between blood samples (at most $10 \mathrm{~h}$ ), it is possible that a short and slight elevation of LH could not be observed on the first day of treatment; nevertheless, in this mare the classical protracted LH surge usually observed was totally abolished. In several species low amplitude surges have been observed with subsequent normal ovulations and luteal phases (rats [22], ewes [30] and women [18]). This is a recent notion which needs to be confirmed in mares as in other species. In the 2 Cetrorelix mares with postponed ovulation, the attenuated $\mathrm{LH}$ surge is the result of $2 \mathrm{LH}$ peaks (one for each mare) but at $24 \mathrm{~h}$ intervals; as in Antarelix mares these surges were in the normal range of values.

The interpretation of the results concerning FSH is more difficult. Antarelix depresses FSH secretion in ovariectomised mares [33], which can be interpreted as a direct effect on the pituitary gland. In intact animals, different effects have been reported: in ewes in the early follicular phase, a GnRH antagonist injected alone has no effect on FSH secretion [10]; this observation is in concordance with the fact that basal FSH release does not acutely depend on GnRH secretion. Similar effects are observed in gilts [4]. But other experiments report an indirect stimulating effect of GnRH antagonists on FSH, caused by a decrease in the negative feedback of estradiol induced by the inhibition of LH: thus when ewes receive the antagonist at the onset of oestrus, an increase in FSH is observed [27]. When ewes are additionally treated with exogenous LH, FSH concentrations are depressed
[10]. Considering that in the mares of the present experiment the mean values of FSH were not affected during the treatment with the antagonist, we can propose that in this species: either Antarelix has no effect, or the absence of effect is the resultant of a negative direct effect on the pituitary gland and a positive indirect effect mediated by the inhibition of LH and estradiol. After the end of the treatment, a period which corresponds to the late oestrous/early dioestrous surge of FSH in control cycles [16], FSH concentrations did not re-increase and remained at a low level. In mares with postponed ovulation these low levels remained until the next ovulation, despite an increase corresponding to the recruitment of the second follicular wave and a decrease corresponding to the follicular dominance. This plasma profile, already observed in mares receiving ORG 30583 [28] was attributed to a direct effect on the pituitary gland. But we also propose that in mares with postponed ovulation, estradiol and inhibin still secreted by the regressing follicle limited the increase of FSH.

\subsection{Effects on follicular growth and ovulation}

In the 5 Antarelix and in 2/5 Cetrorelix treated mares in which LH was strongly depressed and ovulation postponed, the largest follicle which measured $22 \mathrm{~mm}$ at the beginning of the treatment became atretic and failed to ovulate. Since FSH concentrations were not affected, it seems that, as in sheep [6], minimum LH levels are determinant for the terminal follicular growth. Using progesterone to depress LH concentrations during the follicular phase, Gastall et al. [19] suggested that LH is required for the continued growth of the largest follicle after its expression of dominance. Minimum levels of LH seem to be necessary for the production of androgens from the thecal interstitial cells (for conversion to estradiol by the granulosa cells) [7]. In animals with postponed ovulations a new follicular wave 
emerged on the day after the end of treatment, despite the low levels of FSH at this moment and during the 7 previous days. The emergence of this follicular wave also coincided with the restarting of LH secretion. Now it is generally admitted that the FSH profile in mares shows at least one surge during dioestrus, from 18 to 10 days before ovulation, but some authors suggest that the mare can tolerate important variations in FSH levels without an apparent effect on cyclicity [21]. The results of the present experiment confirm that in the mare the emergence of a new follicular wave, after the regression of the dominant follicle only requires minimum fluctuations of $\mathrm{FSH}$ but is subordinate to the elevation of LH. The time for the new recruited follicular wave to ovulate seems quite normal, compared to previous studies [13], since ovulation occurs from 12 to 13 days after the end of treatment. These results also confirm the proposition that small follicles (up to 10 or $15 \mathrm{~mm}$ ) are continuously growing and regressing and thus provide a reservoir for larger follicles [20].

In conclusion, an 8 days treatment with Antarelix during the follicular phase can be used to postpone ovulation for 12 to 13 days in mares. The great depressive effect of this antagonist on LH concentrations during the period of treatment can lead to test this antagonist to control the endogenous secretion of this gonadotrophin during superovulation treatments. The GnRH antagonist induced delay in follicular growth and ovulation in mares confirms the role for $\mathrm{LH}$ in antral follicular development before the preovulatory stage.

\section{ACKNOWLEDGEMENTS}

The authors thank: D. Perrissoud (Asta Medica, Frankfurt, Germany) for the gift of Cetrorelix and R. Deghenghi (Europeptides, Argenteuil, France) for the gift of Antarelix, A.F. Parlow for eLH and eFSH standards, Y. Combarnous (INRA, Nouzilly, France) for eCG antibody and T. Magallon (INRA, Nouzilly, France) for purified eLH, A. Caraty, M.A. Driancourt and
G. Baryl for their advice before the experiment, the staff of the PRMD experimental farm for their assistance with caring for the mares, $\mathrm{S}$. Heuclin and F. Belin for their technical assistance for the gonadotrophin assays, D. André and C. Faggu for the progesterone assay, Y. Cognie for revising the manuscript, and A.M. Wall from the Translation Service (INRA, Jouyen-Josas, France) for revising the English.

\section{REFERENCES}

[1] Albano C., Smitz J., Camus M., RiethmüllerWinzen H., Van Steirteghem P., Devroey P. Comparison of different doses of gonadotropinreleasing hormone antagonist Cetrorelix during controlled ovarian hyperstimulation, Fertil. Steril. 67 (1997) 917-922.

[2] Baril G., Pougnard J.L., Freitas V.J.F., Leboeuf B., Saumande J., A new method for controlling the precise time of occurrence of the preovulatory gonadotropin surge in superovulated goats, Theriogenology 45 (1996) 697-706.

[3] Briant C., Superovulation is associated with endogenous LH depression in mares, 50th Annual Meeting of the European Association for Animal Production, Zurich, Switzerland, 350, Abst H5.9, 1999.

[4] Brüssow K.P., Schneider F., Nürnberg G., Alteration of gonadotrophin and steroid hormone release, and of ovarian function by a GnRH antagonist in gilts, Anim. Reprod. Sci. 66 (2001) 117-128.

[5] Cahoreau C., Combarnous Y., Comparison of two reference preparations for horse chorionic gonadotrophin in four in vivo and in vitro assays, J. Reprod. Fertil. 79 (1987) 281-287.

[6] Campbell B.K., McNeilly A.S., Picton H.M., Baird D.T., The effect of a potent gonadotrphinreleasing hormone antagonist on ovarian secretion of oestradiol, inhibin and androstenedione and the concentration of LH and FSH during the follicular phase of sheep oestrous cycle, J. Endocrinol. 126 (1990) 377-384.

[7] Chappel S.C., Howles C., Reevaluation of the roles of luteinizing hormone and follicle stimulating hormone in the ovulatory process, Hum. Reprod. 6 (1991) 1206-1212.

[8] Cognié Y., State of the art in sheep-goat embryo transfer, Theriogenology 51 (1999) 105-116.

[9] Deghenghi R., Boutignon F., Lenaerts V., Antarelix (EP 24332) a novel water soluble LHRH antagonist, Biomed. Pharmacother. 47 (1993) 107-110.

[10] Dobson H., Campbell B.K., Scaramuzzi R.J. Use of a GnRH antagonist in conjunction with low amplitude, high frequency $\mathrm{LH}$ pulses to induce follicular growth without an LH surge and ovulation in ewes, Anim. Reprod. Sci. (1997) 213-222. 
[11] Driancourt M.A., Locatelli A., Prunier A., Effects of gonadotrophin deprivation on follicular growth in gilts, Reprod. Nut. Dev. 35 (1995) 663-673.

[12] Driancourt M.A., Palmer E., Seasonal and individual effects on ovarian and endocrine responses of mares to a synchronization treatment with progestagen-impregnated vaginal sponges, J. Reprod. Fertil. Suppl. 32 (1982) 283-291.

[13] Driancourt M.A., Palmer E., Time of ovarian follicular recruitment in cyclic pony mares, Theriogenology 21 (1984) 591-600.

[14] Duijkers I.J.M., Klipping C., Willemsen W.N.P., Schneider E., Niebch G., Hermann R., Single and multiple dose pharmacokinetics and pharmacodynamics of the gonadotrophin-realising hormone antagonist Cetrorelix in healthy female volunteers, Hum. Reprod. 12 (1998) 2392-2398.

[15] Erb K., Pechstein B., Schueler A., Engel J., Hermann R., Pituitary and gonadal endocrine effects and pharmacokinetics of the novel luteinizing hormone antagonist teverelix in healthy men: a first-dose-in-humans study, Clin Pharmacol. Ther. 67 (2000) 660-669.

[16] Evans M.J., Irvine C.H.G., Serum concentrations of FSH, $\mathrm{LH}$ and progesterone during the oestrous cycle and early pregnancy in the mare, J. Reprod. Fertil. Suppl. 23 (1975) 193-200.

[17] Fraser H.M., Lunn S.F., Morris K.D., Deghenghi R., Initiation of high dose gonadotrophin-releasing hormone antagonist treatment during the late follicular phase in the macaque abolishes luteal function irrespective of effects upon the luteinizing hormone surge, Hum. Reprod. 12 (1997) 430-435.

[18] Gandar R., Collin D., Pic préovulatoire des gonadotrophines, J. Gynecol. Obstet. Biol. Reprod. 26 (1997) 567-575.

[19] Gastal E.L., Bergfelt D.R., Nogueira G.P., Gastal M.O., Ginther O.J., Role of luteinizing hormone in follicle deviation based on manipulating progesterone concentrations in mares, Biol. Reprod. 61 (1999) 1942-1498.

[20] Ginther O.J., Characteristics of the ovulatory season, in: Reproductive biology of the mare: basic and applied aspects, Equiservices Publishing, Cross plains, 1992, pp. 173-232.

[21] Ginther O.J., Endocrinology of the ovulatory season, in: Reproductive biology of the mare: basic and applied aspects, Equiservices, Cross Plains, 1992, pp. 233-290.

[22] Ishikawa J., Luteinizing hormone requirements for ovulation in the rat, Biol. Reprod. 46 (1992) 1144-1150.

[23] Maclellan L.J., Whyte T.R., Murray A., Fitzpatrick L.A., Earl C.R., Aspden J.E., Grotjan H.E., Wals J., Trigg T.E., D’Occhio M.J., Superstimulation of ovarian follicular growth with FSH, oocyte recovery, and embryo production from zebu (Bos indicus) calves: effects of treatment with a GnRH agonist or antagonist, Theriogenology 49 (1998) 1317-1329.

[24] Madill S., Rieger D., Johnson W.H., Walton J.S., Coy D.H., Rawlings N.C., Effects of an LHRH antagonist on the time of occurrence and amplitude of the preovulatory LH surge, progesterone and estradiol secretion, and ovulation in superovulated holstein heifers, Theriogenology 41 (1994) 951-960.

[25] Nagy P., Huszenicza G.Y., Guillaume D. Reiczigel J., Juhasz J., Palmer E., Kulcsar M., Abavaery K., Factors affecting plasma progesterone concentration and the retrospective determination of the time of ovulation in cyclic mares (submitted).

[26] Oussaid B., Lonergan P., Khatir H., Monniaux D., Touze J.L., Beckers J.F., Cognie Y., Mermillod P., Effect of GnRH antagonist induced prolonged follicular phase on follicular atresia and oocyte developmental competence in vitro in superovulated heifers, J. Reprod. Fertil. 118 (2000) 137-144.

[27] Oussaid B., Mariana J.C., Poulin N., Fontaine J., Lonergan P., Beckers J.F., Cognie Y., Reduction of the developmental competence of sheep oocytes by inhibition of LH pulses during the follicular phase with a GnRH antagonist, J. Reprod. Fertil. 117 (1999) 71-77.

[28] Palmer E., Effet d'un antagoniste de GnRH (ORG 30583) sur l'activité ovarienne cyclique de la jument, Colloque Société Française d'Études sur la Fertilité 26 (1988) 311-320.

[29] Patterson-Bay D.J., Geisert R.D., Hill C.M. Minton J.E., McCann J.P., Morgan G.L., GnRH antagonist inhibition of luteinizing hormone secretion and ovulation in the pig, Anim. Reprod. Sci. 49 (1997) 207-214.

[30] Pau K.Y.F., Kuehl D.E., Jackson G.L., Effect of frontal hypothalamic deafferentation on luteinizing hormone secretion and seasonal breeding in the ewe, Biol. Reprod. 27 (1982) 999-1009.

[31] Pinsky J., Lamharzi N., Halmos G., Groot K., Jungwirth A., Vadillo-Buenfil M., Kakar S.S., Schally A.V., Chronic administration of Luteinizing Hormone-Releasing Hormone (LHRH) antagonist Cetrorelix decreases gonadotrope responsiveness and pituitary LHRH receptor messenger ribonucleic acid levels, Endocrinology 137 (1996) 3430-3436.

[32] Terqui M., Thimonier J., New, fast, radioimmunological method for measuring plasma progesterone level. Application for early pregnancy diagnosis in the ewe and goat, C.R. Hebd. Scéances Acad. Sci., Ser. D, Sci. Nat. 279 (1974) 1109-1112.

[33] Watson E.D., Pedersen H.G., Thomson S.R.M. Fraser H.M., Control of follicular development and luteal function in the mare: effects of a GnRH antagonist, Theriogenology 54 (2000) 599-609. 